\title{
Creating tools for inquiry-based mathematics learning from technological pedagogical content knowledge perspectives: Collaborative design approach
}

\author{
Zhi Ming Yan \\ Ludong University \\ Ching Sing Chai \\ The Chinese University of Hong Kong \\ Hyo-Jeong So \\ Ewha Womans University
}

\begin{abstract}
This study employed the technological pedagogical content knowledge (TPACK) framework to guide the collaborative design process between preservice and practicing teachers. The teams designed technological pedagogical mathematics tools (TPMTs) for inquiry-based learning based on the syllabi for secondary mathematics. The content of the chat messages of preservice and practicing teachers was coded with different dimensions of TPACK to unpack the process of how the teams arrived at critical design decisions. The TPMTs were further evaluated by 30 practicing mathematics teachers, with respect to three criteria: (1) technology tools and curriculum goals, (2) technology tools and teaching activities, and (3) the fit between pedagogy and technology. The content analysis revealed that the collaborative design process involved three clear stages, demarcated by the different versions of the TMPTs: replacement, enhancement, and transformation. Practicing teachers' pedagogical content knowledge played a crucial role in the design of pedagogically sound tools, and for refining the initial TPACK of preservice teachers. The subsequent evaluations supported the positive pedagogical values of the TPMTs. Overall, this study contributes to TPACK research with a case where the collaborative design process with distributed expert knowledge can be synthesised to create pedagogically sound technological tools for mathematics.
\end{abstract}

\section{Introduction}

The technological pedagogical content knowledge (TPACK) framework has emerged as a powerful framework that is quintessential to developing and unpacking teachers' professional knowledge for the technology-infused twenty-first century classroom (Harris, Phillips, Koehler, \& Rosenberg, 2017). Coupled with learning by design, that leverages teachers' existing knowledge as epistemic resources, the TPACK framework helps teachers to develop situated, complex, and integrated understanding about technologyenhanced teaching and learning (Koh, Chai, Wong, \& Hong, 2015; Voogt, Fisser, Roblin, Tondeur, \& van Braak, 2013). While many teacher educators have adopted TPACK as a framework for the design of educational technology courses (e.g., Angeli \& Valanides, 2009a; Koehler \& Mishra, 2005; Koehler, Mishra, \& Yahya, 2007), there are relatively few studies in mathematics teacher education, and these are limited to commonly used software tools such as spreadsheets for preservice teacher education (e.g., Angeli \& Valanides, 2013; Niess, 2013). Currently, utilising the TPACK framework to engage preservice teachers in designing usable digital learning tools for mathematics is rare (Voogt et al., 2013).

Additionally, simply engaging preservice teachers in the design of lesson activities may be insufficient for the creation of quality lesson plans or tools (Koehler \& Mishra, 2005; Koh, Woo, \& Lim, 2013). The cognitive demand of design on preservice teachers is one of the key problems. Good pedagogical design needs to be grounded in rich classroom experiences. Thus, preservice teachers may need to be engaged in a cognitive apprenticeship where they can receive help from expert peers to acquire the necessary knowledge and skills for quality lessons plans and materials (van Velzen \& Volman, 2009). Partnering experienced teachers with preservice teachers to address the lack of pedagogical knowledge is a common suggestion for teacher education programs in the area of educational technology (Lim, Chai, \& Churchill, 2011). Despite the general recognition that experienced teachers could scaffold the preservice teachers' development, little research exists that reports on how practicing teachers promote the design activities of preservice teachers, especially in creating technology-integrated learning tools. 
In this paper, we apply the TPACK framework to unpack how scaffolding from practicing teachers via online discussions has contributed to preservice teachers' design of technological pedagogical mathematics tools (TPMTs) for secondary mathematics topics. Twenty-four 2nd year mathematics preservice teachers enrolled in an educational technology course, worked in groups, and discussed their design with practicing teachers via the Tencent QQ platform (also known as QQ); the favourite instant messaging (IM) software for Chinese users. Their messages were analysed using the TPACK framework to examine how the practicing teachers scaffolded the preservice teachers' TPMTs design. In addition, the TPMTs were evaluated by other practicing teachers not involved in the design phase, to judge their pedagogical quality. In conclusion, we summarise our study's contribution with respect to the value of engaging distributed expert knowledge in the TPACK design process as well as the potential of teacher-generated digitallearning resources through a collaborative design approach.

\section{Literature review}

\section{The challenges of mathematics inquiry-based learning in practice}

In mathematics, inquiry-based learning refers to student-centred learning of the subject that engages students to think and work like mathematicians. The advocates of inquiry-based learning believe that it can help students to develop robust and functional mathematical knowledge, curiosity, and creativity as well as critical analysis and reflection skills (Harlen, 2013). However, during the implementation of inquiry-based learning, mathematics teachers generally encounter some challenges. These can be divided into three aspects: restrictions imposed by the school system, issues of classroom management, and lack of appropriate resources. In particular, the shortage of sufficient and suitable learning resources is one of the critical obstacles for mathematics teachers to implement inquiry-based learning. Mathematical knowledge involves the manipulation of abstract symbols and representations where students often face difficulties to visualise the phenomena. Technological tools for inquiry-based learning have drawn attention from mathematics educators since they can be used as learning resources to support interactive and exploratory learning where students can visualise how their actions change mathematical representations (Drier, 2001). Technological tools such as GeoGebra, allow students to repeatedly test their hypotheses and to develop a deeper understanding of mathematical concepts. However, there is little research concerning the ways teachers can design topic-specific technological tools to facilitate mathematics inquiry-based learning from the TPACK perspective (Voogt et al., 2013). Engaging teachers in designing such technological tools could be part of teachers' professional development activities. When designed appropriately, teacher-designed technological tools can facilitate students’ inquiry-based learning in the classroom.

\section{Creating topic-specific technological tools with TPACK}

Mishra and Koehler (2006) proposed the TPACK framework that builds on Shulman's pedagogical content knowledge (PCK) (Shulman, 1986). According to the TPACK framework, teachers need technological knowledge (TK), pedagogical knowledge (PK), and content knowledge (CK) to design pedagogically sound technology-integrated lessons. The interplay between PK and CK forms teachers' professional PCK that enables them to identify and resolve students' learning difficulties. With the inclusion of TK, technological pedagogical knowledge (TPK) refers to the pedagogically sound use of technological tools, whereas technological content knowledge (TCK) refers to technologically represented content knowledge without necessarily considering pedagogy. Finally, TPACK is formed through the synthesis and transformation of all these knowledge types (Cox \& Graham, 2009). Table 1 presents the operational definitions of the seven dimensions of TPACK used in this paper.

Educators have begun adopting the notion of TPACK as a theoretical framework to design curricula for teacher training to improve pedagogical competence for effective technology integration. A recent review of intervention studies employing the TPACK framework for teacher education and teachers' professional development reported positive outcomes for both preservice and practicing teachers (Voogt et al., 2013). Employing TPACK for the creation of technological tools and environments for learning has not received much attention in TPACK literature. To date, there are only three case studies reported. First, Wu, Chen, Wang, and Su (2008) designed the game-based software engineer educational system for undergraduate computer majors with the integration of TPACK. Wu and his colleagues considered how role-playing as a pedagogical approach supported by game-based technology could enrich the students' learning about 
software engineering. The qualitative evaluation and feedback from 34 subjects supported the usefulness of the TPACK framework in designing an environment for a software engineering curriculum. Second, Wong, Chai, and Zhang (2015) designed a mobile learning environment for learning the Chinese language in a Singaporean primary school. This research unpacked the various forms of TPACK considered for the design of mobile learning platforms. The students who had used the mobile learning environment reported that it was acceptable, easy to use, and useful for their learning. Third, in the study by Lee, Mohamed, and Altamimi (2015), TPACK was employed to design and develop an online tutorial system for helping preservice special educators to learn about Malay braille. The content-based features, pedagogy-based features, technology-based features, and quality of online learning were rated highly by 77 preservice special educators.

Table 1

The construct of TPACK operationalised in this study

\begin{tabular}{ll}
\hline Construct & Description \\
\hline TK & Knowledge about Flash technology \\
PK & Knowledge about inquiry-based learning activities \\
CK & Knowledge about mathematical content matters \\
PCK & Knowledge about inquiry-based learning activities to teach specific mathematical content \\
TCK & Knowledge about representing mathematical content with Flash technology \\
TPK & Knowledge about how Flash technology can be used in inquiry-based learning activities \\
TPCK & Knowledge about using Flash technology to support inquiry-based learning activities in \\
& mathematics \\
\hline
\end{tabular}

The technological tools developed in the studies above were rather large-scale learning systems involving researchers, practicing teachers, and software developers. While these studies supported that distributed expertise in TPACK could contribute to the creation of quality technology tools, they did not explicate the various forms of TPACK each party had contributed to the design of the technological tools and how the knowledge resources were synthesised through collaborative design. Attending to the specific contribution of TPACK knowledge has been identified as an important research gap in advancing this field of study (Heitink, Voogt, Fisser, Verplanken, \& van Braak, 2017). Heitink et al.'s recent study focuses specifically on eliciting the teachers' TPK through their pedagogical reasoning for the use of ICT. We argue, on the other hand, that it is important to unpack how practicing teachers' PCK contributes to the design of subjectspecific technological tools. This can enrich the existing body of research on the TPACK theoretical framework with respect to practicing teachers' design competency (Koehler et al., 2007). Unravelling design interactions has been identified as an important research area for TPACK as it may contribute to a better understanding of the design processes and principles in order to further advance teachers' TPACK (Boschman, McKenney, \& Voogt, 2015; Koh \& Chai, 2016).

\section{Research context}

\section{Research participants and topics}

This research is a development and evaluation study conducted in China, with the aim to develop a series of topic-specific technological tools for inquiry-based learning of secondary school mathematics. The requirements of primary and secondary mathematics curricula in China include four parts: (1) numbers and algebra, (2) space and graphics, (3) statistics and probability, and (4) the integrated application of mathematics (Ministry of Education of the People's Republic of China, 2012). The curricula standards state that learning mathematics should go beyond imitating, memorising, and practicing. Instead, mathematics' curricula should encourage students to engage in meaningful learning activities such as observing, experimenting, speculating, reasoning, communicating, and reflecting to enable the development of their mathematical thinking skills and to improve their problem-solving abilities.

Based on the curricula standards, the current mathematics textbooks present the subject content with inquiry-based learning activities that generally require students to observe, do, discuss, and think. Figure 1 is an example of a do activity in the secondary mathematics textbook for grade 6 (Shandong Province Edition, 2007). In this hands-on activity, the students need to build an object with five cubes, view the object from different angles, and draw its main, top, and side views. 


\section{Doing}

Build some objects with cubic blocks, as shown below.

(1) View the object you build from different directions.

(2) Draw the main view, top view and left view of the object.
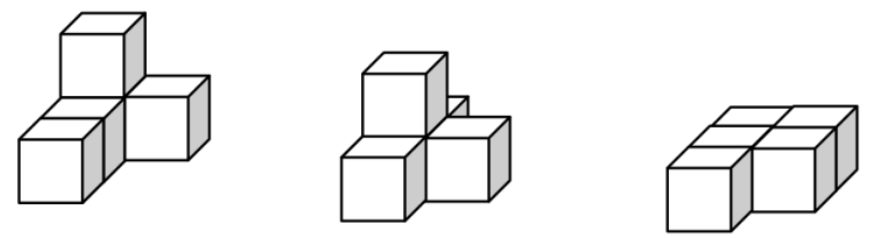

Figure 1. Do activity from the mathematics textbook (Shandong Province Edition, 2007) for grade 6

Although several teaching materials (e.g., physical cubic blocks) and learning activities are clearly described in the textbook, teachers are generally reluctant to implement inquiry-based learning activities in the classroom. The main reasons include: (a) teachers face issues with classroom management and learning efficiency because of large class sizes (around 50 students per class); (b) preparing, distributing, and collecting the teaching materials is troublesome; and (c) instructors tend to believe that teaching materials are good for hands-on activities, but do not for helping students to understand the mathematical principles.

Recognising such difficulties in the use of the existing mathematics textbook and resources, this research aims to design and to evaluate technological tools that can be easily integrated with the teaching of specific mathematical topics. Thus, six inquiry-based mathematical topics (Table 2) were selected for the creation of technological pedagogical mathematics tools (TPMTs). The selection of these topics was based on the perceived pedagogical needs from practicing teachers and on the general assessment that Flash technology is useful for creating interactive learning resources. Twenty-four preservice mathematics teachers, five secondary practicing mathematics teachers, and two educational technology instructors formed a collaborative design community to co-develop the TPMTs with the Adobe Flash program, which was chosen because: (a) the interactive affordance of Flash objects can support exploration in inquiry-based learning; and (b) because the script language of Adobe Flash has a similar grammar structure as the $\mathrm{C}++$ language, which the preservice mathematics teachers had learned previously. The whole design and development process lasted for 7 weeks.

Table 2

The mathematical topics in this research

\begin{tabular}{ll}
\hline Topics & Textbook Source \\
\hline Topic 1: Viewing from different directions & Grade 6 \\
Topic 2: The Pythagorean theorem & Grade 7 \\
Topic 3: Buffon's needle experiments & Grade 8 \\
Topic 4: Central symmetric figure & Grade 7 \\
Topic 5: Densely paving with a planar graph & Grade 7 \\
Topic 6: Making a rectangular solid & Grade 6 \\
\hline
\end{tabular}

\section{Collaborative design process}

Six online collaborative design groups were formed with consideration given to different geographical locations. Each design group included one practicing teacher, one university-based educational technology instructor, and four preservice teachers. Each preservice teacher was only involved in one topic and each practicing teacher was also involved in one topic, except one teacher working on two topics. The collaborative design teams communicated with each other through the QQ application, where the discussion for each topic was only open to directly involved participants. Online collaboration was chosen since it was difficult to coordinate face-to-face meetings and it makes communication anytime and anywhere possible. During the first week, the practicing teachers shared the topic-related materials with the group members, 
which included digital textbooks, presentation slides, and lesson plans that they had used in teaching. The preservice teachers took 2 weeks to get acquainted with the materials and to study how Flash technology could be utilised with the support from educational technology instructors. In the third week, the preservice teachers suggested their own lesson plans and ideas about the TPMT to be developed. Group discussions ensued in week four to reach consensus on design decisions and the preservice teachers designed the TPMTs for the next 3 weeks. Online discussion between preservice and practicing teachers lasted during all 7 weeks.

\section{Guiding design principles of TPMTs}

Design is a cognitively demanding task. The following design principles, drawn from the literature, guided the overall pedagogical and technological design.

- $\quad$ Principle 1: To use technology for active and constructive mathematics inquiry. Technology can transform abstract concepts to concrete representations, which can facilitate students' reasoning and learning processes (Cheng, 2002; Jonassen, Beissner, \& Yacci, 1993) by offloading and distributing cognitive learning processes (Sedig, \& Liang, 2006). Furthermore, interactive tools allow learners to be actively engaged in the exploration and construction of mathematical concepts. Some researchers, however, argue that only well-designed tools can effectively involve students and support their learning of mathematics (Liang, \& Sedig, 2010). Thus, careful design is needed to develop high-quality tools for mathematics.

- $\quad$ Principle 2: To select authentic pedagogical problems for design initiation. The design of TMPTs should begin with authentic pedagogical problems arising from the difficulties that teachers face when implementing inquiry-based leaning activities without technology or from their dissatisfaction with students' learning outcomes. Koehler and Mishra (2005) argued that an authentic pedagogical problem is a rich context for designers to weave knowledge of technology, content, and pedagogy together. Authentic pedagogical problems can provide teachers with the design context to develop their TPACK, on which design decisions in the TPMT development are based.

- $\quad$ Principle 3: To draw out relevant TPACK knowledge through discussion for design support. The quality of the designed TPMT depends highly on the knowledge that is considered during the collaborative design process. Since such collective knowledge is distributed among design team members, it is necessary to encourage participants to explicate and contribute relevant TPACK aspects (Koehler, Mishra, \& Yahya, 2007; Wong et al., 2015). Drawn from the existing literature on the criticality of TPACK in action and in collaborative discourse, this study adopted the principle of encouraging all participants to articulate relevant knowledge for the collaborative TPMT design.

\section{Research questions}

In this paper, we describe how the practicing and preservice teachers co-designed and created TPMTs for inquiry-based learning in mathematics as guided by the TPACK framework. Methodologically, the online discussions among the team members were content-analysed to examine the process of making design decisions and the emergence of TPACK. This was followed by the end users' evaluation of the created TPMTs’ pedagogical usefulness. The research questions were:

1. How did the preservice and practicing mathematics teachers collaborate with regard to various dimensions of TPACK for reaching critical design decisions in the TPMTs' design?

2. How did mathematics teachers perceive the integration of pedagogy and technology in the TPMTs that were collaboratively designed by the preservice and experienced teachers?

\section{Data collection and analyses}

Prior to data collection, the consent forms stating the purpose and procedures of the study were obtained from the participants. To address research question 1, we collected the online chat messages among the preservice and practicing teachers. Content analysis was performed according to Koehler et al. (2007). The unit of analysis was an utterance (Stahl, 2011). Two researchers coded each utterance independently using 
the definition of TPACK in Table 1 to identify the knowledge types that each member contributed. The overall inter-rater agreement was $86 \%$, and disputed codes were discussed until consensus was reached between the two coders. Their codes were compared, and the percentage of codes that were the same was used to generate the overall inter-rater agreement. We then proceeded to search for patterns in the design processes to determine how the various dimensions of TPACK emerged. This qualitative analysis process helped to identify distinctive design stages, which were marked by different prototypes.

To answer research question 2, we administered a questionnaire adapted from the Technology Integration Assessment Rubric (TIAR) (Harris, Grandgenett, \& Hofer, 2010), to 30 mathematics teachers practicing in secondary schools to examine their perceptions of the developed TPMTs' quality. These teachers had not participated in the collaborative design process. Furthermore, we conducted focus group interviews with nine secondary practicing mathematics teachers to obtain comments about the TPMTs. For the interviews, three questions were asked: (1) What is your first impression of the TPMTs? (2) What effects do you think these TPMTs may have on teaching activities? and (3) What effects do you think these TPMTs may have on student learning? The interview data were content-analysed to find common themes emerged from multiple responses.

\section{Findings}

\section{Patterns of design decisions in TPACK}

This study illustrates the design processes of one particular TPMT case: "viewing from different directions" (topic 1, grade 6). The discourse processes that led to the design decisions and the various TPACK forms that the teachers employed were coded. Table 3 provides a succinct account of the progressive design process, where we extracted only relevant data from the QQ discussion. We assigned all participants individual numbers to distinguish them, additionally labelled by Pre-T (preservice teacher) and Pra-T (practicing teachers). The TPMT creation processes of the other topics are presented in Table 4. During the content analysis of the chat messages, we found some emerging patterns in the co-design process demarcated by the different TMPT versions. These were categorised as three stages: replacement, enhancement, and transformation (for simplicity, RET). Each stage is represented by a functional prototype as shown in Figures 2, 3, and 4.

The first pattern of design decisions (DD) was categorised as replacement, which refers to the type of design that aims to replace existing resources. Before discussing with the practicing teachers, the preservice teachers had read the mathematics textbook and learned the details about the learning activities in the topic "viewing from different directions". When they realised the potential difficulties of exploring with physical cubes, they began to think about how to solve the problems by designing a technological tool with Flash script technology. This was the stage where the initial design decision (DD1) was formed. As illustrated in Figure 2, the DD1 initially led the team to design a tool intended to replace the physical cubes with digital 3-dimensional (3D) ones. The design mimics the lesson activities described in Figure 1. Both the preservice and the practicing teachers draw on the existing knowledge embedded in the textbook without considering significant changes in any part, which was considered as the simple replacement of existing material/ideas with technology. 
Table 3

The design decisions, collaborative design discourse, and TPACK contribution of teachers in the design processes of the TPMT "viewing from different directions"

Design decision (DD) Collaborative design discourse $\quad$ TPACK contribution by preservice and

DD1: Flash-Drag-
Object

Object

Creating virtual 3D

cubes with Flash for teachers or students to build a 3D object. This design replaces the physical cubes with virtual cubes.
"We plan to make the small virtual cube which can be copied and dragged." (PreT1) "Good idea!” (Pra-T)

"On the one hand, teacher can show a 3D object, then students draw its three views using paper and pen; on the other hand, teacher can draw the views of a 3D object on the blackboard, then students build the corresponding object with Flash.” (PreT1)

"Students can experience how to visualise e a 3D object from its front, top, and left views.” (Pre-T1)

"The object created doesn't need too many layers. Stacking three layers is enough.” (Pra-T)

"The number of layers is up to you (practicing teacher). Any layer number is OK.” (Pre-T3)

\begin{tabular}{l}
\hline DD2: Flash-Draw- \\
Views \\
Replacing DD1, DD2 \\
creates a drawing \\
function for the three \\
views of the object built \\
directly with Flash.
\end{tabular}

"Let students draw (with paper and pens). That is required in an examination." (Pre$\mathrm{T} 2)$

"Let students draw them out with Flash. It is difficult to share if drawing on paper." (Pra-T)

"You can give nine blank grids and let the students draw the three views by clicking the grids.” (Pra-T)

"Imagine it, views can be drawn in the grids.” (Pra-T) practicing teachers

Knowledge about Flash scripting

technology (TK from preservice teachers)

Knowledge of using 3D cubes to support the object-building activity (Creating the click-and-drop 3D cubes is TK while the object-building activity is an existing PCK suggested by the textbook. The combination constitutes TPACK from preservice teachers)

Knowledge about using traditional paperand-pencil methods or chalkboards to support a view-drawing activity. (PCK from preservice teachers)

Knowledge of how many layers for object construction would suffice with traditional physical cubes. (PCK from practicing teachers)

The knowledge of Flash scripting technology to create 3D cubes. (TK from preservice teachers)

Knowledge about the requirement for an examination (PCK from preservice teachers)

The knowledge of the disadvantage of drawing views with paper and pens (PCK from practicing teachers)

Knowledge about drawing the views with pens on the grid paper in classroom (PCK from practicing teachers) is given as a technological expression. (TPACK from practicing teachers)

\begin{tabular}{|c|c|c|}
\hline \multirow{2}{*}{$\begin{array}{l}\text { DD3: Flash-Check- } \\
\text { Views } \\
\text { Building a further } \\
\text { enhanced feedback } \\
\text { mechanism to provide } \\
\text { the correct answer about } \\
\text { the views to the created } \\
\text { object }\end{array}$} & $\begin{array}{l}\text { "After building, click the button to } \\
\text { display the three views." (Pre-T4) } \\
\text { "Let the computer give the correct } \\
\text { answer." (Pra-T) }\end{array}$ & $\begin{array}{l}\text { Knowledge about using Flash to support } \\
\text { users for checking the correct answer to } \\
\text { the three views corresponding to the built } \\
\text { object (TPACK from both preservice and } \\
\text { practicing teachers) }\end{array}$ \\
\hline & $\begin{array}{l}\text { "Because of arbitrary dragging, the script } \\
\text { for the correct answer for views is not } \\
\text { easy." (Pre-T2) } \\
\text { "Not so hard, it is just a technical } \\
\text { problem, it will be solved.” (Pre-T4) } \\
\text { "For technical problems, you can consult } \\
\text { an educational technology [instructor].” } \\
\text { (Pra-T) }\end{array}$ & $\begin{array}{l}\text { Knowledge about Flash scripting } \\
\text { technology (TK from the preservice } \\
\text { teachers) }\end{array}$ \\
\hline $\begin{array}{l}\text { DD4: Flash-Input- } \\
\text { Object } \\
\text { Transforming the } \\
\text { current inquiry-based } \\
\text { learning by creating an } \\
\text { input function that can } \\
\text { generate 3D objects and } \\
\text { the three views based } \\
\text { on numerical values. }\end{array}$ & $\begin{array}{l}\text { "I want to fill in the numbers in the grid } \\
\text { and let the students draw three views.” } \\
\text { (Pra-T) } \\
\text { "It would be very good if numbers could } \\
\text { be input in the grid.” (Pra-T) } \\
\text { "Inputting numbers is no problem.” (Pre- } \\
\text { T4) } \\
\text { "Text inputting does not ask for help } \\
\text { from others. We have learned it.” (Pre- } \\
\text { T1) }\end{array}$ & $\begin{array}{l}\text { Knowledge about teaching an activity of } \\
\text { imaging the object from the abstract } \\
\text { number of cubes and then drawing the } \\
\text { corresponding views (PCK from } \\
\text { practicing teachers) } \\
\text { Knowledge about text input in Flash } \\
\text { scripting technology (TK from preservice } \\
\text { teachers) }\end{array}$ \\
\hline
\end{tabular}


Next, an idea evolved and the subsequent decision DD2 enhanced DD1 by allowing users to draw the top, front, and side views using the 9-squares grid after they had built the 3D flash objects (Figure 2). The use of the 9-squares grid is considered a PCK embedded in the textbook. Creating this 9-squares grid allows both students and teachers to interact with the Flash objects in both 3D and 2D representations, which may indicate the synthesis of the practicing teachers' PCK and the preservice teachers' TK.

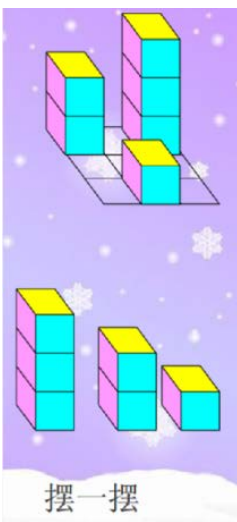

Drag the cubes

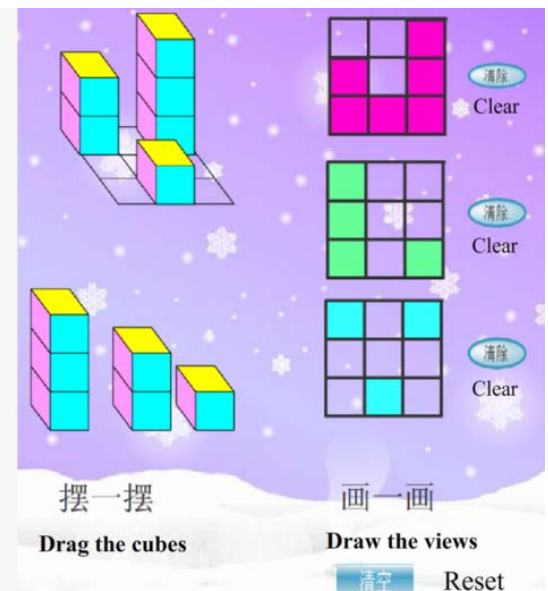

Reset

Figure 2. Interfaces of the designed Flash objects that led to DD1 and DD2 in topic 1

DD3 enhanced DD2 by providing automated means of checking the answers of the 3D and 2D representations in the Flash object (Figure 3). We identified this design as enhancement because DD3 intends to increase the efficiency of teaching processes by providing more opportunities for practice and self-checking by students.

In DD4, identified as transformation, the concrete 3D objects were substituted by numbers, and the new TPMT empowered students to deal with the subject matter through abstract thinking (Figure 4) Students input a number to represent the cubes to be stacked up in the 9-square grids, visualise the 3D objects mentally, and attempt to draw the views. Dealing with numbers is arguably an element of mathematical thinking. The final design is transformative, because it surpasses the textbook representation and reaches a new way of representing the subject matter requiring higher-order problem-solving skills.

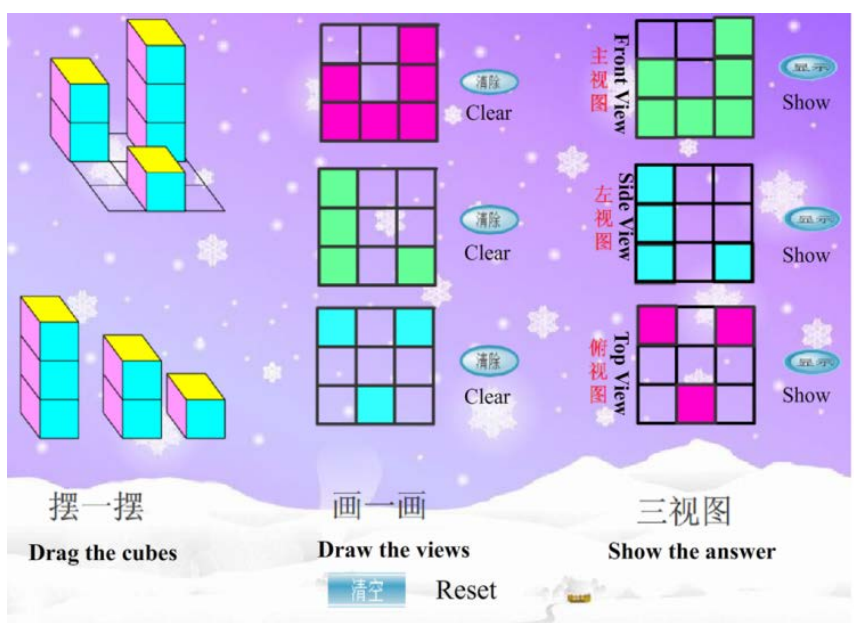

Figure 3. Interface of the designed Flash object that led to DD3 in topic 1 


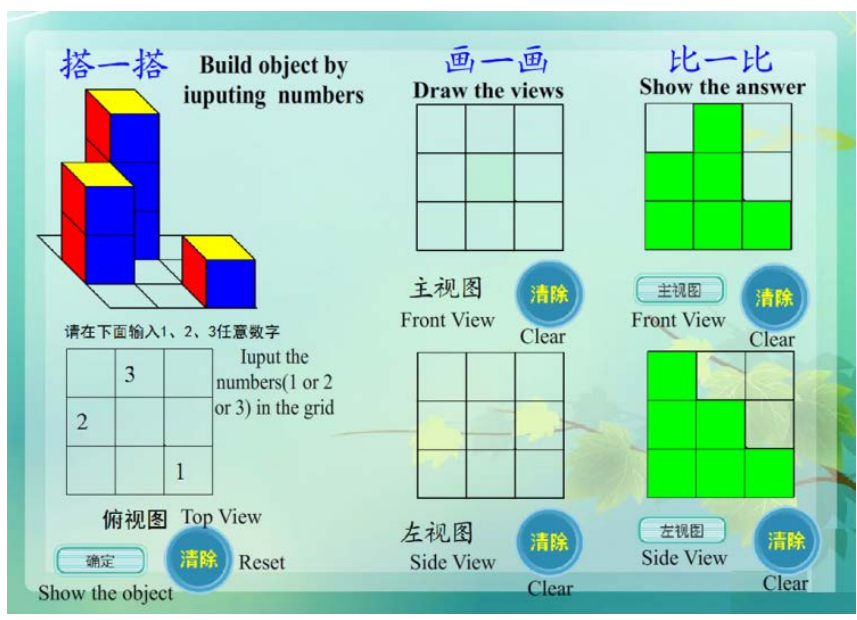

Figure 4. Interface of the designed Flash object that led to DD4 in topic 1

\section{TPACK in the design process}

With regard to how teachers' knowledge was articulated in a given design situation, both the preservice teachers and the practicing teachers shared a common understanding of the mathematical inquiry-based activities as represented in the textbook. The analysis of QQ messages in DD1 revealed that the preservice teachers contributed more in terms of the affordances of Flash technology such as the copy-and-drag function in DD1 and, at times to creating the representations of the different views (TCK). The preservice teachers' understanding of PCK, however, was restricted in their use of technology as a means to enhance learning. They may need deeper PCK to be able to use technology effectively and creatively. In DD2, while the preservice teachers felt the need to draw the different views for a paper-based examination (PCK), the practicing teachers had a deeper understanding about the disadvantage of such exercises (PCK). The practicing teachers insisted on providing students with the 9-grids space (PCK) to represent the different views by simply clicking on the Flash object (TK). This solution allows students to actively construct many 2D representations for the different views of what they saw in a 3D form (TPACK). DD3 illustrates yet another scenario where both the preservice and practicing teachers agreed on the need to provide students with a means for self-checking of their various views' on representations. For this solution, which was beyond the preservice teachers' technical skills, the educational technologists' contribution in terms of scripting (TK) was necessary. In DD4, the PCK of the practicing teachers again played a pivotal role in creating the transformative TPMT. In sum, the practicing teachers' deeper PCK anchored the design with the various TPACK dimensions to be constructed with the preservice teachers' TK and TCK. The analyses of design decisions made by the other five design teams are summarised in Table 4.

Table 4

All design decisions in the remaining five cases

\begin{tabular}{|c|c|c|c|}
\hline Topics & Design Decisions (DD) & TPACK contribution & Design stage \\
\hline \multirow[t]{2}{*}{$\begin{array}{l}\text { The } \\
\text { Pythagorean } \\
\text { theorem }\end{array}$} & $\begin{array}{l}\text { DD1: Creating several right triangles with } \\
\text { Flash for students to prove the Pythagorean } \\
\text { Theorem }\end{array}$ & $\begin{array}{l}\text { Preservice teachers’ } \\
\text { TK/TCK/TPACK \& } \\
\text { practicing teachers’ } \\
\text { PCK }\end{array}$ & Replacement \\
\hline & $\begin{array}{l}\text { DD2: Adding drawing tools to DD1 which } \\
\text { can be used to draw lines for the facilitation } \\
\text { of proving the Pythagorean Theorem with } \\
\text { the right triangles. }\end{array}$ & $\begin{array}{l}\text { Preservice teachers’ } \\
\text { TK \& practicing } \\
\text { teachers’ PCK }\end{array}$ & Enhancement \\
\hline \multirow[t]{2}{*}{$\begin{array}{l}\text { Buffon's } \\
\text { needle } \\
\text { experiments }\end{array}$} & $\begin{array}{l}\text { DD1: Creating a simulation to replace an } \\
\text { actual needle-throwing situation }\end{array}$ & $\begin{array}{l}\text { Practicing teachers' } \\
\text { PCK \& preservice } \\
\text { teachers' TK }\end{array}$ & Replacement \\
\hline & $\begin{array}{l}\text { DD2: Building an enhancement function for } \\
\text { counting the probability value of the needles } \\
\text { and the lines intersecting and displaying the } \\
\text { corresponding } \pi \text { value. }\end{array}$ & $\begin{array}{l}\text { Practicing teachers' } \\
\text { PCK }\end{array}$ & Enhancement \\
\hline
\end{tabular}




\begin{tabular}{|c|c|c|c|}
\hline \multirow[t]{2}{*}{$\begin{array}{l}\text { Central } \\
\text { symmetric } \\
\text { figure }\end{array}$} & $\begin{array}{l}\text { DD1: Creating a series of rotatable graphics } \\
\text { with Flash to replace the ones made of paper } \\
\text { or wood for students to observe. }\end{array}$ & $\begin{array}{l}\text { Practicing teacher's } \\
\text { PCK }\end{array}$ & Replacement \\
\hline & $\begin{array}{l}\text { DD2: Enhancing DD1 by creating a function } \\
\text { that can display the angle value at which the } \\
\text { graphic has rotated relative to its initial } \\
\text { position. }\end{array}$ & $\begin{array}{l}\text { Practicing teacher' } \\
\text { PCK \& preservice } \\
\text { teachers' TK }\end{array}$ & Enhancement \\
\hline \multirow[t]{3}{*}{$\begin{array}{l}\text { Densely } \\
\text { paving with } \\
\text { a planar } \\
\text { graph }\end{array}$} & $\begin{array}{l}\text { DD1: Creating some virtual triangles and } \\
\text { quadrilaterals by cloning one original } \\
\text { triangle and one original quadrilateral; the } \\
\text { cloned graphs can be dragged to any place } \\
\text { and rotated in order to support students' } \\
\text { paving activity. }\end{array}$ & $\begin{array}{l}\text { Practicing teachers' } \\
\text { TK/PCK }\end{array}$ & Replacement \\
\hline & $\begin{array}{l}\text { DD2: Enhancing DD1 by making one of the } \\
\text { original triangles' and two of the original } \\
\text { quadrilaterals' vertexes movable; thus, all } \\
\text { triangles and quadrilaterals are available. }\end{array}$ & $\begin{array}{l}\text { Practicing teachers’ } \\
\text { PCK \& preservice } \\
\text { teachers' TK }\end{array}$ & Enhancement \\
\hline & $\begin{array}{l}\text { DD3: Transforming the inquiry-based } \\
\text { learning by adding a splitting function that } \\
\text { can generate irregular graphics not included } \\
\text { in the textbook. }\end{array}$ & $\begin{array}{l}\text { Practicing teachers' } \\
\text { PCK }\end{array}$ & Transformation \\
\hline \multirow[t]{3}{*}{$\begin{array}{l}\text { Making a } \\
\text { rectangular } \\
\text { solid }\end{array}$} & $\begin{array}{l}\text { DD1: Creating a virtual paper with Flash to } \\
\text { replace the fixed-size physical paper (side } \\
\text { length }=20 \mathrm{~cm} \text { ) in the textbook for students } \\
\text { to make a rectangular solid. The virtual } \\
\text { paper's four corners can be cut off by } \\
\text { inputting the side length of the corners. }\end{array}$ & $\begin{array}{l}\text { Preservice teachers' } \\
\text { TPACK }\end{array}$ & Replacement \\
\hline & $\begin{array}{l}\text { DD2: Enhanced DD1 by displaying the } \\
\text { rectangular solid's volume. }\end{array}$ & $\begin{array}{l}\text { Practicing teachers' } \\
\text { PCK }\end{array}$ & Enhancement \\
\hline & $\begin{array}{l}\text { DD3: Transforming the current inquiry- } \\
\text { based learning by creating a virtual paper } \\
\text { that allows the user to determine the size of } \\
\text { the paper. }\end{array}$ & $\begin{array}{l}\text { Practicing teachers' } \\
\text { PCK }\end{array}$ & Transformation \\
\hline
\end{tabular}

\section{Replacement, Enhancement \& Transformation (RET) design stages in other cases}

The remaining TPMT creation processes were analysed to examine if RET patterns were replicated in other design cases. As illustrated in Table 4, the results of the content analysis showed that the RET patterns were found in two of the other five cases. In the case of "making a rectangular solid" (topic 6), there were three design decisions that belonged to the replacement, enhancement and transformation stage respectively. DD1 resulted in the design that replaced the physical paper with the virtual paper, which could be used to make a rectangular solid. DD2 enhanced the TPMT by displaying the volume of the created rectangular solid. DD3 is transformative because it surpassed a fixed-size paper in the textbook and allowed students to explore mathematical laws in a broader way.

The RET pattern was also detected in "densely paving with a planar graph" (topic 5). DD1 led to the design that replaced the physical triangles and quadrilaterals with virtual triangles and quadrilaterals, which could be used to support students' paving activities. DD2 involved making one vertex of the triangle and two vertexes of the quadrilateral movable, which allows students to make any triangle and quadrilateral by moving movable vertexes. DD2 is seen as an enhancement. DD3 is transformative because it allows students to further explore dense paving with irregular graphics beyond the regular graphics used in the textbook, achieved by adding the splitting function to the graphics.

Taken together, the RET pattern was found in three out of the six cases while the remaining ones only reached the enhancement stage. In these cases (i.e., "central symmetric figure”, "the Pythagorean theorem”, and "Buffon's needle experiments"), the first prototype designed was all about replacing the physical objects. After the first prototype, the designs were respectively enhanced by automating some aspects of 
the displayed data so that students can focus on making sense of the mathematical information rather than physically measuring it. In sum, the design of all the TPMTs demonstrated a progressive process, involving design thinking ideas about replacement, enhancement, and transformation with technology.

\section{Practicing teachers' evaluations on the TPMTs' integration level}

To evaluate the TPMTs' integration level created by the design teams, we applied our Technology Tools Integration Assessment Rubric (TTIAR), which was adapted from the TIAR (Harris et al., 2010). The four criteria in TIAR are: (1) curriculum goals \& technology, (2) instructional strategy \& technologies, (3) technology selection(s), and (4) fit among content, pedagogy, and technology together.

TTIAR was developed through discussion with two TPACK experts, with the following adaptations. Firstly, the term technologies were replaced with technology tools to customise the rubric for the TPMTs' context. Secondly, we used inquiry-based teaching activities instead of instructional strategy, because the former was easier for Chinese teachers to understand the concept and more focused on the nature of TPMTs. Thirdly, the technology selection(s) criterion was removed, because all the developed TPMTs were based on Flash technology. Hence, TTIAR included three criteria: (1) technology tools and curriculum goals, (2) technology tools and teaching activities, and (3) fit (curriculum goals, inquiry-based teaching activities, and technology tools). The rubric applied a 4-point score as shown in Table 5.

Table 5

Descriptions of TTIAR (Technology Tools Integration Assessment Rubric) dimensions and criteria

\begin{tabular}{|c|c|c|c|}
\hline Criteria & $\begin{array}{l}\text { Technology tools \& } \\
\text { curriculum goals }\end{array}$ & $\begin{array}{l}\text { Technology tools \& } \\
\text { teaching activities }\end{array}$ & $\begin{array}{l}\text { Fit (curriculum goals, inquiry-based } \\
\text { teaching activities, and technology } \\
\text { tools) }\end{array}$ \\
\hline 4 & $\begin{array}{l}\text { Technology tools are } \\
\text { strongly aligned with } \\
\text { curriculum goals. }\end{array}$ & $\begin{array}{l}\text { Technology tools } \\
\text { optimally support } \\
\text { inquiry-based teaching } \\
\text { activities. }\end{array}$ & $\begin{array}{l}\text { Curriculum goals, inquiry-based } \\
\text { teaching activities, and technology } \\
\text { tools fit together strongly. }\end{array}$ \\
\hline 3 & $\begin{array}{l}\text { Technology tools are } \\
\text { aligned with curriculum } \\
\text { goals. }\end{array}$ & $\begin{array}{l}\text { Technology tools } \\
\text { support inquiry-based } \\
\text { teaching activities. }\end{array}$ & $\begin{array}{l}\text { Curriculum goals, inquiry-based } \\
\text { teaching activities, and technology } \\
\text { tools fit together. }\end{array}$ \\
\hline 2 & $\begin{array}{l}\text { Technology tools are } \\
\text { partially aligned with } \\
\text { curriculum goals. }\end{array}$ & $\begin{array}{l}\text { Technology tools } \\
\text { minimally support } \\
\text { inquiry-based teaching } \\
\text { activities. }\end{array}$ & $\begin{array}{l}\text { Curriculum goals, inquiry-based } \\
\text { teaching activities, and technology } \\
\text { tools somewhat fit together. }\end{array}$ \\
\hline 1 & $\begin{array}{l}\text { Technology tools are not } \\
\text { aligned_with curriculum } \\
\text { goals. }\end{array}$ & $\begin{array}{l}\text { Technology tools do not } \\
\text { support inquiry-based } \\
\text { teaching activities. }\end{array}$ & $\begin{array}{l}\text { Curriculum goals, inquiry-based } \\
\text { teaching activities, and technology } \\
\text { tools do not fit together. }\end{array}$ \\
\hline
\end{tabular}

Table 6

Descriptive statistics of six TPMTs' average integration level

\begin{tabular}{llc}
\hline Criteria & $M$ & $S D$ \\
\hline Technology tools \& curriculum goals & 3.28 & .65 \\
Technology tools \& teaching activities & 3.16 & .72 \\
Fit (curriculum goals, inquiry-based teaching activities, and technology tools) & 3.15 & .69 \\
\hline
\end{tabular}

We recruited 30 practicing mathematics teachers in secondary schools to evaluate the quality of the six TPMTs developed by the collaborative design teams. Regarding internal consistency reliability, the overall Cronbach's alpha of the teachers' evaluation was .85. Table 6 shows descriptive statistics for each criterion used to assess the TPMTs. The results indicate that the TPMTs evaluated by the teachers aligned with curriculum goals ( $M=3.28)$, supported inquiry-based teaching activities $(M=3.16)$, and the fit among the TPMTs, curriculum goals, and teaching was good $(M=3.15)$. Since all ratings are above the mid-point of 2.5, this may imply that the designed TPMTs demonstrate an acceptable level of technological and pedagogical integration. 


\section{Discussion}

Since its inception, TPACK has been used as a guiding framework to help preservice teachers design subject-specific technology-integrated learning activities. Most reported TPACK interventions tend to engage preservice teachers in designing lesson plans without the creation of digital artefacts (Angeli \& Valanides, 2009a; Niess, 2013). Another strand of TACPK research that uses the TPACK framework to create digital resources (e.g., Lee et al., 2015; Wong et al., 2015; Wu et al., 2008) dealt with design by experts, but without the involvement of preservice teachers. This study reported an alternative way to engage preservice teachers in creating TPACK through collaborative design and by making usable digital resources. We argue that engaging preservice teachers in such design work can be a form of authentic learning that deepens their understanding of both pedagogy and technology.

In this study, we examined the two research questions concerning: (a) the collaborative design process between preservice teachers and practicing teachers, and (b) the perceived value of the technological tools (TPMTs) collaboratively designed by preservice teachers and practicing teachers. Regarding the first research question, we found that preservice teachers who possess relevant technical abilities such as programming skills can work with in-service teachers, who have strong content and pedagogical knowledge, to produce usable TMPTs. Three design principles formulated from the literature were employed to guide the preservice and practicing teachers' collaborative design work effort. Regarding the first principle "use to use technology for mathematics inquiry", both preservice and practicing mathematics teachers were able to contribute in a distributed manner to construct TPMTs that can facilitate inquiry-based learning in mathematics. Setting such design challenges for the preservice and practicing teachers resulted in the active use of TK and PCK for the construction of usable TPMTs. In terms of the second principle "to draw out relevant TPACK knowledge through discussion to support design”, findings from the content analysis showed that the online discussion was an effective way for preservice and practicing teachers to make design decisions in the development of TPMTs. While the QQ discussions were brief, they seem sufficient in drawing out relevant knowledge for contributing to pedagogically-sound design. Lastly, the third principle "to design for authentic pedagogical problems" served as an effective anchoring point for the participants to design technological tools to gain ecological validity in the classroom. Our findings are consistent with the prior research that has emphasized identifying authentic problems as a starting point for the design of technology integration in the context of preservice teacher education (Angeli \& Valanides, 2009b).

In terms of the design process, these design principles, however, were insufficient to make the design process more efficient as all the initial designs were at the replacement level. The content analysis of the online collaborative design discourse revealed that design is an iterative process, and that the old design begets the new design (Petroski, 2012). In this research, each group of preservice teachers initially proposed a TPMT prototype prior to discussing with the practicing teachers. Though the initial prototypes were always a replacement design, they prompted the practitioners to reflect on their expertise and to articulate further insights (Porayska-Pomsta et al., 2012). The iterations of design moved from replacement to enhancement and, at times, to transformation. This process may reveal that once the prototype is created, it objectifies and operationalises the initially articulated set of knowledge and frees up the teachers' mind to consider more knowledge resources for subsequent creation. Each prototype seems to lay the foundation for the iteration of the next design. The progression from replacement to enhancement to transformation could be seen as a design talk back (Fischer, 2000). Given our findings, however, it may be possible to help the design teams to skip or minimise the replacement stage by articulating design decisions with appropriate prompts such as how the design can value-add to the curriculum activities beyond changing the current representation in the textbook/curriculum materials. Alternatively, future research may consider formulating design principles such as "to articulate the added pedagogical value of the design features before building the prototype" to see if the replacement stage can be skipped and the possibility for transformative design to emerge can be enhanced.

Regarding the second research question, we evaluated six technological tools (TPMTs) designed by the pre-service and practicing teachers for secondary school students' inquiry-based learning in mathematics. The positive ratings of the TPMTs given by other practicing teachers implied that the design principles were generally sound in guiding the design process. The teachers rated highly about both practical and pedagogical values of TPMTs, highlighting the design feature that is based on authentic problems to facilitate inquiry learning activities. While the teachers still need to design specific student-centred learning 
activities (Angeli \& Valanides, 2009a), the TPMTs enabled inquiry-based learning of mathematics to be more feasible in classrooms. We also speculate that the high ratings about the use of TPMTs in the classroom are associated with their topic-specific design ready for use in the classroom. In our study, distributed expertise between the preservice and practicing teachers was leveraged to design useful TPMTs. In particular, the contributions from practicing teachers were critical to ensure the ecological validity of TPMTs for classroom integration. Similar to previous research (Wong et al., 2015), this study showed that practicing teachers' PCK played a crucial role in the TPMTs' design since the development of integrated, sophisticated TPACK was promoted (Koehler et al., 2007) through either an integration with preservice teachers' TK or a refinement of the initial TPACK of the preservice teachers.

\section{Conclusion}

Findings from this work have important implications for teacher preparation and teacher professional development. First, given that this study shows that the three design principles can facilitate the production of usable technological tools, teacher educators and teacher professional development communities that are targeted at designing technological tools may consider using them to guide design effort. Second, this study demonstrates that it is possible to engage preservice and in-service teachers who are located in geographically different areas to work collaboratively in a design project. While fostering collaborative relationships between preservice and in-service teachers is not a new idea in teacher education, geographical and logistical barriers have been major impediments to expand the use of such a collaborative learning mechanism in practices. Leveraging the affordances of mobile devices and social network services, this study suggests that preservice and in-service teachers can engage in flexible learning environments where they can be easily connected beyond the limitations in time and locations. Third, this study suggests a new pedagogical model that can benefit both preservice and practicing teachers. The collaborative design process employed in this study is rather different from the existing collaborative learning method (e.g., collaborative action research, mentoring), which assumes preservice teachers as novices who need to learn from expert teachers (Levin \& Rock, 2003). This study demonstrates the importance of mutual learning experiences where preservice and in-service teachers can learn from each other's expertise.

Some limitations of the study should be noted. An obvious limitation of this study is that it adopts a case study approach, and thus the findings may not be generalisable to other settings. In this case, the preservice teachers and the educational technologists possess programming skills, which is not typical for most teacher education institutes. Future research should explore the viability of collaborative design among participants with a varying degree of technical skills. Nonetheless, for institutes that offer programming courses in the context of teacher education, this case study offers a possible model for teacher professional development. The second limitation of this case study is that it was more inclined towards usability testing in verifying the TPMTs pedagogical usefulness. As Harris et al. (2017) pointed out, the current TPACK research has moved into the realms of knowing and doing. Future research can look into how teachers make sense of the designed TPMTs (or other similar tools) to create lessons and structure student-centred activities (see also Angeli \& Valanides, 2009a); and consequently, how the lessons are enacted and reflected in action and after action, as a further means to refine the designed tools. Such work may prompt the formulation of additional design principles for the creation of TPMTs or the lesson design processes.

In conclusion, this study contributes to the field of technology-enhanced learning in two ways. First, the design guidelines can be adopted as a method to design TPMTs that have the potential to enhance or transform inquiry-based learning in mathematics. Our research also demonstrated possible solutions to reduce the effort needed for technology integration in schools by creating topic-specific technological tools with TPACK. Second, the study unpacked how teachers' distributed TPACK contributed to the critical design decisions in the developmental process of the TPMTs. Illuminating design processes has been identified as important to future TPACK research (Boschman et al., 2015; Koh \& Chai, 2016). Furthermore, the RET design pattern can enrich the theoretical framework of TPACK in the context of designing technology-integrated learning products/environments. Overall, this study suggests that educators need to consider how to engender transformative design by thinking beyond PCK embedded in curricula. 


\section{Acknowledgements}

This work was funded by Shandong Provincial Education Department (Project ID: 2015M062) and Department of Science \& Technology of Shandong Province (Project ID: 2013YD01031), PR China.

\section{References}

Angeli, C., \& Valanides, N. (2009a). Epistemological and methodological issues for the conceptualization, development, and assessment of ICT-TPACK: Advances in technological pedagogical content knowledge (TPACK). Computers \& Education, 52(1), 154-168. https://doi.org/10.1016/j.compedu.2008.07.006

Angeli, C., \& Valanides, N. (2009b). Examining epistemological and methodological issues of the conceptualizations, development and assessment of ICT-TPACK: Advancing Technological Pedagogical Content Knowledge (TPCK)-Part I. Teachers. Proceedings of the American Educational Research Association (AERA) Annual Conference. San Diego, CA.

Angeli, C., \& Valanides, N. (2013). Technology mapping: An approach for developing technological pedagogical content knowledge. Journal of Educational Computing Research, 48(2), 199-221. https://doi.org/10.2190/EC.48.2.e

Boschman, F., McKenney, S., \& Voogt, J. (2015). Exploring teachers' use of TPACK in design talk: The collaborative design of technology-rich early literacy activities. Computers and Education, 82(C), 250-262. https://doi.org/10.1016/j.compedu.2014.11.010

Cheng, P. C. H. (2002). Electrifying diagrams for learning: Principles for complex representational systems. Cognitive Science, 26(6), 685-736. https://doi.org/10.1207/s15516709cog2606_1

Cox, S., \& Graham, C. R. (2009). Diagramming TPACK in practice: Using an elaborated model of the tpack framework to analyze and depict teacher knowledge. TechTrends, 53(5), 60-69. https://doi.org/10.1007/s11528-009-0327-1

Drier, H. S. (2001). Teaching and learning mathematics with interactive spreadsheets. School Science and Mathematics, 101(4), 170-179. https://doi.org/10.1111/j.1949-8594.2001.tb18020.x

Fischer, G. (2000). Symmetry of ignorance, social creativity, and meta-design. Knowledge-Based Systems, 13(7-8), 527-537. https://doi.org/10.1016/S0950-7051(00)00065-4

Harlen, W. (2013). Inquiry-based learning in science and mathematics. Review of Science Mathematics \& ICT Education, 7(2), 9-33.

Harris, J., Grandgenett, N., \& Hofer, M. (2010). Testing a TPACK-based technology integration assessment rubric. Retrieved from http://publish.wm.edu/bookchapters/6

Harris, J., Phillips, M., Koehler, M., \& Rosenberg, J. (2017). TPCK/TPACK research and development: Past, present, and future directions. Australasian Journal of Educational Technology, 33(3), i-viii. https://doi.org/10.14742/ajet.3907

Heitink, M., Voogt, J., Fisser, P., Verplanken, L., \& van Braak, J. (2017). Eliciting teachers’ technological pedagogical knowledge. Australasian Journal of Educational Technology, 33(3), 96109. https://doi.org/10.14742/ajet.3505

Jonassen, D. H., Beissner, K., \& Yacci, M. (1993). Structural knowledge: Techniques for representing, assessing, and acquiring structural knowledge. Hillsdale, NJ: Lawrence Erlbaum Associates.

Koehler, M. J., \& Mishra, P. (2005). Teachers learning technology by design. Journal of Computing in Teacher Education, 21(3), 94-102.

Koehler, M. J., Mishra, P., \& Yahya, K. (2007). Tracing the development of teacher knowledge in a design seminar: Integrating content, pedagogy and technology. Computers \& Education, 3(49), 740762. https://doi.org/10.1016/j.compedu.2005.11.012

Koh, J. H. L., \& Chai, C. S. (2016). Seven design frames that teachers use when considering technological pedagogical content knowledge (TPACK). Computers \& Education, 102(C), 244-257. https://doi.org/10.1016/j.compedu.2016.09.003

Koh, J. H. L., Chai, C. S., Wong, B., \& Hong, H. Y. (2015). Technological pedagogical content knowledge (TPACK) and design thinking: A framework to support ICT lesson design for 21st century learning. The Asia-Pacific Education Researcher, 24(3), 535-543. https://doi.org/10.1007/s40299015-0237-2

Koh, J. H. L., Woo, H. L., \& Lim, W. Y. (2013). Understanding the relationship between Singapore preservice teachers' ICT course experiences and technological pedagogical content knowledge (TPACK) through ICT course evaluation. Educational Assessment, Evaluation and Accountability, 25(4), 321-339. https://doi.org/10.1007/s11092-013-9165-y 
Lee, L. W., Mohamed, A. R., \& Altamimi, A. A. (2015). Design, development, and evaluation of an automated e-Learning tutorial system to instruct pre-service special educators in the Malay Braille code. Asia-Pacific Education Researcher, 24(3, SI), 481-494. https://doi.org/10.1007/s40299-014$\underline{0219-9}$

Levin, B. B., \& Rock, T. C. (2003). The effects of collaborative action research on preservice and experienced teacher partners in professional development schools. Journal of Teacher Education, 54(2), 135-149. https://doi.org/10.1177/0022487102250287

Liang, H. N., \& Sedig, K. (2010). Can interactive visualization tools engage and support pre-university students in exploring non-trivial mathematical concepts? Computers and Education, 54(4), 972-991. https://doi.org/10.1016/j.compedu.2009.10.001

Lim, C. P., Chai, C. S., \& Churchill, D. (2011). A framework for developing pre-service teachers' competencies in using technologies to enhance teaching and learning. Educational Media International, 48(2), 69-83. https://doi.org/10.1080/09523987.2011.576512

Ministry of Education of the People's Republic of China. (2012). Mathematics curriculum standards for compulsory education (2011 Edition). Beijing: Beijing Normal University Press.

Mishra, P., \& Koehler, M. J. (2006). Technological pedagogical content knowledge: A framework for teacher knowledge. The Teachers College Record, 108(6), 1017-1054. https://doi.org/10.1111/j.14679620.2006.00684.x

Niess, M. L. (2013). Central component descriptors for levels of technological pedagogical content knowledge. Journal of Educational Computing Research, 48(2), 173-198. https://doi.org/10.2190/EC.48.2.d

Petroski, H. (2012). Petroski on engineering - design begets design. Design News, 67(12), 14. Retrieved from https://www.designnews.com/automation-motion-control/petroski-on-engineering-designbegets-design/137351473032792

Porayska-Pomsta, K., Frauenberger, C., Pain, H., Rajendran, G., Smith, T., Menzies, R., ... Lemon, O. (2012). Developing technology for autism: An interdisciplinary approach. Personal and Ubiquitous Computing, 16(2), 117-127. https://doi.org/10.1007/s00779-011-0384-2

Sedig, K., \& Liang, H.-N. (2006). Interactivity of visual mathematical representations: Factors affecting learning and cognitive processes. Journal of Interactive Learning Research, 17(2), 179-212.

Shulman, L. S. (1986). Those who understand: Knowledge growth in teaching. Educational Researcher, 15(2), 4-14. https://doi.org/10.3102/0013189X015002004

Stahl, G. (2011). How I view learning and thinking in CSCL groups. Research \& Practice in Technology Enhanced Learning, 6(3), 137-159.

van Velzen, C., \& Volman, M. (2009). The activities of a school-based teacher educator: a theoretical and empirical exploration. European Journal of Teacher Education, 32(4), 345-367. https://doi.org/10.1080/02619760903005831

Voogt, J., Fisser, P., Roblin, N. P., Tondeur, J., \& van Braak, J. (2013). Technological pedagogical content knowledge-a review of the literature. Journal of Computer Assisted Learning, 2(29), 109-121. https://doi.org/10.1111/j.1365-2729.2012.00487.x

Wong, L. H., Chai, C. S., Zhang, X., \& King, R. B. (2015). Employing the TPACK framework for researcher-teacher co-design of a mobile-assisted seamless language learning environment. IEEE Transactions on Learning Technologies, 8(1), 31-42. https://doi.org/10.1109/TLT.2014.2354038

Wu, W.-H., Chen, W.-F., Wang, T.-L., \& Su, C.-H. (2008). Developing and evaluating a game-based software engineering educational system. International Journal of Engineering Education, 24(4), 681-688.

Corresponding author: Zhi Ming Yan, jimmy_yan@163.com

Australasian Journal of Educational Technology (C) 2018.

Please cite as: Yan, Z. M., Chai, C. S., \& So, H.-J. (2018). Creating tools for inquiry-based mathematics learning from technological pedagogical content knowledge perspectives: Collaborative design approach. Australasian Journal of Educational Technology, 34(4), 57-71.

https://doi.org/10.14742/ajet.3755 